\section{In praise of deaneries}

\author{
John Launer
}

If you look at the foot of this article, you will see that my address is given as the London Deanery. This is possibly appearing there for the last time. I am not retiring just yet, but the structure of our institution is about to change, and possibly the name will do so too. This gives me an opportunity to write about deaneries, and why they have been such a force for good. In case you are unsure, deaneries are departments of postgraduate medical and dental education. Each is headed by a postgraduate dean, and they are called deaneries for the simple reason that it is easier than spelling out the full designation which is a bit of a mouthful and has 30 consonants in it. They have nothing at all to do with religion, which confuses people who have only heard the word before to describe the place where the dean of a cathedral lives.

Every region in the UK has a deanery. Some also look after postgraduate education for other health professions, including nurses. Each deanery is affiliated to a university, but its funding comes entirely from the National Health Service (NHS). If you are a junior doctor, a deanery will manage your training from the moment you graduate from medical school until the day you receive full accreditation as a specialist or a general practitioner (GP), usually a period of between 5 and 8 years. The London Deanery looks after around 12000 young doctors during this phase of their lives, organising their recruitment into foundation or specialty training posts, allocating their placements in hospitals or the community, reviewing their career progression and awarding them certificates when they complete their training. We also look after their clinical teachers-several thousand of them-trying to make sure that they have adequate training and are properly equipped to act as clinical and educational supervisors.

I could easily spend the rest of this article expatiating on the many and varied functions that deaneries carry out, but you can find this out from their websites, including the excellent one from the London Deanery. ${ }^{1}$ I could also go into a great deal of detail about how deaneries have merged, demerged or re-merged

Correspondence to Dr John Launer, London Department of Postgraduate Medical Education, London Deanery, Stewart House, London WC1B 5DN, UK: jlauner@londondeanery.ac.uk over the past decade, and how they have had to adapt their functions according to political fashion and ministerial dictates, but you can find this information elsewhere too. ${ }^{2} 3$ It would detract from understanding the essence of a deanery's role. We are, to use a phrase coined by our much-loved outgoing dean 'doctors to doctors', in the educational rather than the clinical sense. We look after young doctors as they pass through their years of postgraduate training.

\section{A WEEK'S WORK}

Concrete descriptions are always easier to follow than abstractions, so rather than telling you what our mission statement is, let me give you an account of what I have been up to this week, as a fairly typical member of the deanery's medical staff.

On Monday I taught all day on a course on educational leadership. The course group includes 10 clinical teachers from hospital trusts or GP practices around London, and nearly all of them combine a medical career with a significant commitment to improving training programmes on their patches. The next day I was up at the crack of dawn to travel across London to visit a paediatric department. I sat in on their handover meeting, listening to the junior doctors from the night-time rota handing over to their colleagues on the day shift, with nearly all their consultants present and offering ideas and suggestions. I was there with a deanery colleague, as part of a programme to enhance training standards after a period of organisational turbulence and huge clinical service pressures on the hospital.

I spent most of the following 2 days completing a handbook for directors of medical education in all the hospitals in London, on the best ways of managing bullying and undermining when it happens to trainees. This is a problem the deanery regards as unacceptable and we have a 'zero tolerance' policy towards it. I hope to spend the next few months doing hands-on work on this issue, meeting trainers to help them take a more liberal approach, and talking with trainees about how to tell us confidentially when they are being intimidated. Finally, on Friday our team manager and I carried out a review of the 20 or so grass-roots projects we are currently involved in. I then joined two consultants (a psychiatrist and a chest physician) who are learning to train their hospital colleagues in better educational techniques. Two academics were present as well: they are part of a network of educators who support our projects on a freelance basis. In the same week, other members of this network were involved in training sessions on reflective practice, on supervision skills and using simulation.

It was a representative week for me. Although I work in the specialised area of faculty development, it would be fairly typical of how all my other medical colleagues spend their time at their deanery-although their role might be to focus on one specialty or part of London rather than the specific area of faculty development as I do. I believe it would be representative of what our counterparts do across the UK. All of this activity is supported, of course, by a work force of professional management and administrative staff who are focused on exactly the same task as ours: looking after trainees so they can look after patients better.

\section{FOCUSED ON EDUCATION}

There are some unique features of the way deaneries have been organised, and the way we have worked. Although we organise medical education in the same way as the undergraduate medical schools, we have until now not been tied to any hospital or group of hospitals, nor any single university college. This has given us independence, and also meant that the professional staff have always been drawn from working clinicians who genuinely have a passion for teaching. We have also been free from the domination of either clinical service or academic research, and have been able to concentrate on protecting and improving education. Although there have been errors in the way we have done this-the notorious Medical Training Application System or MTAS was the worst ${ }^{4}$-deaneries have also brought about huge improvements to postgraduate medical education during the 15 years or so that they have been around.

If as a UK trainee you have gone through a proper selection procedure, can see a clear structure to your training years, undergo regular reviews of your progression and have teachers who are trained and accredited in their educational roles as well as their clinical ones, then a deanery has played a leading part in making sure this happens. In addition, a deanery will also be visiting your trust every year, and maybe even your own particular training programme, to make sure they are delivering the education they are paid to deliver. Along with the training programme director and director of 
medical education, they will be fighting for the standards and quality of local education against all the pressures that can pull in the opposite direction. When you fill in the questionnaire for the National Trainee Survey each year, there will be people at your deanery looking at the responses, noting any reported shortcomings, and trying to do something about them. Occasionally, when trusts persistently offered poor education in some specialties, deaneries have even withdrawn trainees and placed them elsewhere.

\section{DEANERIES IN FLUX}

As I indicated, deaneries are now in flux. Some of our roles are being handed over to new bodies called Local Education and Training Boards (LETBs). This is part of a government programme intended to increase local accountability and competition in education, in parallel to similar change in clinical services. In most parts of the country LETBs will cover much the same territory as the deaneries they replace, and retain a similar identity. However, London is being divided up into three boards, so the situation here is more disruptive. Some of our central services will remain because of the economies of scale and also, we hope, a reluctance to split up teams that work extremely well and have accumulated a great deal of experience and wisdom. However, these are anxious times, and our working lives will be different. It would be dishonest to claim that we expect everything to get better and nothing to get worse. Meanwhile, I will suspend judgement. I have worked for a total of 35 years in the NHS, nearly all of them as a clinical GP. For the past 10 of these I have also been at the London Deanery. It is a good moment to state that I have never worked in a better run organisation, and I regard the work there as having being just as worthwhile, and just as gratifying, as being a clinician.
Competing interests None.

Provenance and peer review Commissioned; internally peer reviewed.

To cite Launer J. Postgrad Med J 2013;89:243-244.

Postgrad Med J 2013;89:243-244.

doi:10.1136/postgradmedj-2013-131876

\section{REFERENCES}

1 http://www.londondeanery.ac.uk/ (accessed 17 Feb 2013).

2 London Deanery. Changes to Medical Education in London: a guide for doctors in training. London: London Deanery, 2011. http://www.londondeanery.ac. uk/global-news/changes-to-medical-education-inlondon-a-guide-for-doctors-in-training (accessed 17 Feb 2013).

3 Department of Health. Liberating the NHS: developing the health care workforce. London: Department of Health, 2012 http://www.dh.gov.uk/prod_consum_dh/ groups/dh_digitalassets/documents/digitalasset/ dh_132087.pdf (accessed 17 Feb 2013).

4 Launer J. From my diary. Ed Prim Care 2007:18;658-9 http://repository.tavistockandportman. ac.uk/150/1/J_Launer___From_my_diary_ (EPC_2007_3_proof).pdf (accessed 17 Feb 2013). 